\title{
O (DES)LUGAR DA PEDAGOGIA E DA DIDÁTICA NA FORMAÇÃo DOS PROFESSORES
}

\author{
EL (DES)LUGAR DE LA PEDAGOGÍA Y DE LA DIDÁCTICA EN LA \\ FORMACIÓN DE LOS PROFESORES
}

\section{THE PLACE(NESSLESS) OF PEDAGOGY AND DIDACTICS IN THE TEACHER TRAINING}

\author{
Osmar Hélio Alves ARAÚJO ${ }^{1}$ \\ Janine Marta Coelho RODRIGUES ${ }^{2}$ \\ Wilson Honorato ARAGÃO ${ }^{3}$
}

RESUMO: Este artigo discute a relação que deve existir entre a pedagogia, a didática e a formação dos professores das diversas áreas do conhecimento, seja ela inicial ou contínua, pois parte da compreensão que são necessários componentes curriculares na formação dos professores que foquem o fazer docente, o fenômeno educativo e as práticas pedagógicas docentes. Para tanto, após considerar pesquisas e ensaios relevantes sobre o tema e considerando o objetivo de discorrer sobre o lugar da pedagogia e da didática na formação docente, o presente artigo discute aspectos que emergem em face desta temática, tais como: a formação didático-pedagógica docente; pedagogia enquanto ciência da educação; didática como campo teórico do ensino; e, sobretudo, busca entrecruzar a pedagogia, a didática e a formação dos professores. Por fim, sublinha-se que a formação dos professores, na maioria das vezes, não ocorre de modo articulado à pedagogia e que, por consequência, muitos docentes não conseguem construir saberes pedagógicos necessários à docência. À vista dessa constatação, este trabalho se encerra reiterando a compreensão que deve existir uma estreita relação entre a formação dos professores, a pedagogia e a didática, pois compreende-se que estes são campos indivisíveis.

PALAVRAS-CHAVE: Pedagogia. Didática. Formação docente.

RESUMEN: Este artículo discute la relación que debe existir entre la pedagogía, la didáctica y la formación de los profesores de áreas distintas del conocimiento, sea ella inicial o continua, pues parte de la comprensión de que son necesarios componentes curriculares en la formación de los profesores que enfoquen el hacer docente, el fenómeno educativo y las prácticas pedagógicas docentes. Para estos, después de

\footnotetext{
${ }^{1}$ Doutorando em Educação pela Universidade Federal da Paraíba (UFPB). Atualmente é professor da Universidade Regional do Cariri (URCA). Email: osmar.araujo@urca.br

${ }^{2}$ Doutora em Educação pela Universidade Federal do Rio Grande do Norte (UFRN). Atualmente é professora titular, Classe E, da Universidade Federal da Paraíba (UFPB), atuando na linha de Pesquisa de Politicas Educacionais do Programa de Pós-Graduação - Mestrado e Doutorado. Email: jmcoelho@ig.com.br

3 Doutor em Educação pela Universidade Federal do Rio Grande do Norte (UFRN). Atualmente é professor Associado II da Universidade Federal da Paraíba, Diretor do Centro de Educação/UFPB (20132016). Email: wilsonaragao@ hotmail.com
} 
considerar investigaciones y ensayos relevantes acerca del tema y considerando el objetivo de discurrir sobre el lugar de la pedagogía y de la didáctica en la formación docente, el presente artículo discute aspectos que emergen frente a esta temática, tales como: la formación didáctico-pedagógica docente; pedagogía como ciencia de la educación; didáctica como campo teórico de enseñanza; y sobre todo, buscar entrecruzar la pedagogía, la didáctica y la formación de los profesores. Por fin, subrayase que la formación de los profesores, en la mayoría de las veces, no ocurre de manera articulada a la pedagogía y que, por consecuencia, muchos docentes no logran construir saberes pedagógicos necesarios a la docencia. En vista de esta constatación, este trabajo termina reiterando la comprensión que debe existir una estrecha relación entre la formación de los profesores, la pedagogía y la didáctica, ya que es comprendido que estos son campos indivisibles.

PALAVRAS-CLAVE: Pedagogia. Didáctica. Formación docente.

ABSTRACT: This article address to the relation that should exist between Pedagogy, Didactics and the teaching training of several areas of knowledge, whether initial or continuous, as it goes from the comprehension that curricular components that focus in the teaching know-how, the educational phenomena and the pedagogic practices are needed. For so, after considering researches and essays relevant to the subject and considering the aim of arguing about the place of Pedagogy and Didactics in the teacher training, the present article discuss the aspects that emerge in light of this topic, such as: the didactic-pedagogic teacher training; pedagogy as an educational science; didactics as a theoretic field of teaching; and, overall, to search to intercross pedagogy, didactics and teacher training. At last, it is highlighted that teacher training, most of the time, does not occur linked to pedagogy and, by so, that many teachers cannot build the needed pedagogical knowledges to the teaching profession. In the light of this ascertainment, this works ends reiterating the comprehension that it should exist a close relation between teacher training, pedagogy and didactics, as it is comprehended that these are inseparable fields.

KEYWORDS: Pedagogy. Didactics. Teacher training.

\section{Introdução}

Não podemos começar este artigo sem antes destacar a nossa compreensão acerca da pedagogia e da didática, haja vista que a linha condutora desta discussão é a busca por articulações entre a formação dos professores ${ }^{4}$, a pedagogia e a didática. Franco, Pimenta e Libâneo (2011), Franco (2008) Franco e Pimenta (2012), entre outros

\footnotetext{
${ }^{4}$ No texto, utilizamos o termo formação dos professores/formação docente para advogar o lugar de destaque da pedagogia e da didática não somente nos cursos de licenciatura das diversas áreas, mas também na formação contínua dos professores. Daí o uso do termo o (des)lugar da pedagogia e da didática na formação dos professores para fazer alusão a quase ausência e, na maioria das vezes, a pouca efetividade da disciplina de didática na formação docente, conforme Pimenta et al (2017), Brandão (2002), dentre outros autores.
} 
teóricos contemporâneos, ancoram nossa base conceitual. A partir da incursão por suas obras compreendemos a pedagogia como a ciência da educação e, por isso, voltada para a práxis ${ }^{5}$ educativa. Logo, a pedagogia abarca e investiga o fenômeno educativo em seus múltiplos aspectos, conteúdos e métodos da educação, procedimentos investigativos, dentre outros. Entendemos a didática como um conjunto teórico de estudos e pesquisas voltadas essencialmente para a fundamentação dos processos de ensino e aprendizagem, enquanto prática social, emancipatória e política. Daí cumpre destacar, em síntese, nossa compreensão de que uma formação docente articulada à pedagogia e à didática contribui para a formação de um professor que constrói e reconstrói a sua prática por meio da reflexão crítica de pensar a prática a partir da própria prática em suas múltiplas nuances.

Destarte, como nos aponta Candau (2008), deve haver necessariamente componentes curriculares na formação dos professores que foquem o fazer docente, o processo educativo e as práticas pedagógicas. Logo, sublinha-se aqui o lugar de destaque que a pedagogia e a didática devem ocupar na formação dos professores. Uma atuação docente desvinculada destes campos limita o fenômeno educativo, enquanto prática social complexa, inibe a construção dos saberes docentes didáticos-pedagógicos, impedindo que o professor se desenvolva como intelectual e, por consequência, apequena o seu papel social, pois passa a assumir a função de um mero técnico executor e transmissor de conteúdos previamente selecionados.

Posto isso, este artigo sublinha que os processos formativos dos professores devem se ancorar principalmente na pedagogia e na didática, pois, como afirma Pimenta (2012, p. 29), “[...] cabe à pedagogia oferecer direção para certa atividade humana: a educação". E cabe à didática, enquanto campo da pedagogia, tomar o ensino como prática social e, acima de tudo, levar os professores a construírem práticas pedagógicas transformadoras.

Para tanto, os escritos de Pimenta (1999, 2012), Brandão (2002), Pimenta e Anastasiou (2002), Libâneo (2002, 2006), Franco (2008, 2012, 2015), Candau (2008) Franco e Gilberto (2011), Franco, Libâneo e Pimenta (2011), Franco e Pimenta (2012), Araújo e Ribeiro (2016), Gatti (2016), Mascarenhas e Franco (2017), Pimenta, Fusari,

\footnotetext{
${ }^{5}$ Neste texto, "A práxis é compreendida a partir da filosofia marxista como uma atitude (teórica-prática) humana de transformação da natureza e da sociedade. Não basta conhecer e interpretar o mundo (teórico),é preciso transformá-lo (práxis). Entender a práxis como prática é uma percepção reduzida, pois nem toda prática transforma a realidade. A práxis é uma atividade transformadora, consciente e intencionalmente realizada" (MASCARENHAS E FRANCO, 2017, p.47).
} 
Pedroso, Pinto (2017) vêm ao encontro das questões que permeiam esta discussão e servem como fundamento para as reflexões que desenvolveremos ao longo deste trabalho.

\section{Contextualizando o debate}

Nas escolas brasileiras há professores com formação desvinculada da pedagogia e da didática, outros com formação frágil em relação aos conhecimentos didático-pedagógicos, assim como há aqueles sedentos por conhecimentos das referidas áreas. Isso ocorre devido à formação pedagógica dada aos docentes nas universidades não ser suficiente para que cumpram seus deveres nos espaços escolares, assim como por não desfrutarem de plenos direitos de uma formação contínua ancorada no campo da pedagogia e da didática, dentre outros campos. Libâneo (2002) corrobora com essa tese assinalando que:

Boa parte dos professores formadores de professores (filósofos, sociólogos, psicólogos e, até, especialistas no ensino de disciplinas) desconhece a necessidade de que suas disciplinas se convertam em saberes pedagógicos, ou se recusam a isso, pelo que formulam conteúdos distanciados dos problemas concretos das salas de aula, empobrecendo a especificidade desses saberes, muitas vezes substituídos pela discussão de temas fragmentados - linguagem, gênero, interdisciplinaridade, diversidade cultural - dissociados do campo conceitual da pedagogia e da didática e, por isso mesmo, resultando em visões reducionistas (LIBANEO, 2002, p. 15-16).

A partir das contribuições de Libâneo (2002), consideramos que a formação dos professores, na maioria das vezes, não ocorre articulada à pedagogia, enquanto ciência da educação, levando a um desfalque nos conhecimentos da pedagogia e da didática, o que faz emergir dificuldades em seu cotidiano e, por consequência, interfere nos processos de ensino e aprendizagem. Libâneo (2006) adverte, entretanto, que os professores necessitam continuamente de uma formação pedagógica, crítica, engajada e que propicie a compreensão teórica dos problemas cotidianos, assim como os instrumentalize para o fazer docente.

Uma revisitação em trabalhos produzidos em diferentes momentos, como: Pimenta (1999), Libâneo (2002), Franco (2008, 2012), Candau (2008) Franco e Pimenta 
(2012), Gatti (2016), Mascarenhas e Franco (2017), Pimenta et al (2007), ao mesmo tempo que confirma essa assertiva, evidencia a emergência de uma formação docente articulada à pedagogia e à didática, posto que os referidos campos têm papel importante na formação do professor, como profissional que precisa construir saberes especializados e pedagógicos ${ }^{6}$, e na construção da sua identidade docente. Esta é uma questão que se impõe diante das exigências crescentes em torno da melhoria do ensino e da formação dos professores. Por isso, ao discutirmos aqui a formação docente, queremos sublinhar a indissociabilidade entre a pedagogia, a didática e a formação dos professores.

A compreensão apresentada no parágrafo anterior nos faz ressaltar, apresentando as palavras de Franco e Pimenta (2012. p. 07), que “[...] as escolas estão fragilizadas e não conseguem ensinar tudo a todos; os educadores defrontam-se com a questão do que ensinar; os professores, com o como ensinar; e toda sociedade ainda não tem resposta para a questão para que ensinar?". Nesse sentido, as contribuições dos autores nos permitem ampliar o espectro da discussão sobre a pedagogia e a didática como componentes constitutivos da formação e da construção da identidade docente. A pedagogia, nesse sentido, associada ao caráter formativo da didática, fortalece a formação dos professores, possibilita a mobilização e a construção de saberes pedagógicos ${ }^{7}$, bem como permite aos professores criarem e recriarem suas práticas com protagonismo e militância pedagógica.

Franco e Gilberto (2011) entram neste debate lembrando que aqueles que trabalham com formação docente podem perceber o desespero de professores diante do seu próprio despreparo profissional, pois participando de cursos de formação contínua, não se sentem preparados para empreender mudanças na prática, não conseguem apreender saberes básicos e nem construírem os saberes pedagógicos necessários à docência. As contribuições das autoras fazem lembrar que é crescente o número de professores sem a necessária formação didático-pedagógica.

A emergência da discussão sobre o professor pesquisador e o professor reflexivo no contexto educacional, sobretudo brasileiro, reacende o debate em torno do lugar da pedagogia e da didática na formação docente. Entretanto, trata-se de uma

${ }^{6}$ Pimenta e Anastasiou (2002, p. 71) advertem que “[...] nos processos de formação dos professores, é preciso considerar a importância dos saberes das áreas de conhecimento [...], dos saberes pedagógicos [...], dos saberes didáticos [...], dentro outros".

${ }^{7}$ Pimenta (1999), entre outros teóricos, busca aclarar o conceito de saberes pedagógicos, os definindo como sendo os saberes da teoria da educação, saberes sobre relação educação-sociedade, e, ainda, como sendo os saberes sobre organização da escola e sobre o processo de ensino e aprendizagem. 
discussão permeada por controvérsias, com opiniões divergentes, como observam Mascarenhas e Franco (2017), quanto à pedagogia como uma área de conhecimento com saber próprio, até a concepção que a reduz a um curso de licenciatura, conforme orientação da Diretriz Curricular Nacional de Pedagogia.

As ideias defendidas por Pimenta (2012), Libâneo (2006), Franco, Libâneo e Pimenta (2011), Franco (2008, 2012, 2015), Franco e Pimenta (2012), em relação à pedagogia como uma área de conhecimento com saber próprio, expressam, em boa parte, as preocupações que motivaram este estudo em torno deste tema: o (des)lugar da pedagogia e a da didática na formação dos professores. Nosso estudo, todavia, também considerou o alerta feito por Brandão (2002) em relação ao ensino da didática nos cursos de formação de professores. Segundo o autor:

\begin{abstract}
A didática destes cursos é inútil. Os professores entrevistados não souberam nem citar nenhum livro ou autor de didática, de que tenham se servido para subsidiar a prática docente. Nem mesmo destacar algo do conteúdo da disciplina, que lhes tenha sido de valia. Nunca recorreram a tais livros a não ser por ocasião de "concursos públicos". Nenhum soube citar um professor de didática, ou de licenciatura, que tivesse marcado sua formação (BRANDÂO, 2002, p. 59)
\end{abstract}

Pimenta et al $(2017)^{8}$ identificaram, a partir de pesquisa que investigou as fragilidades na formação inicial do professor polivalente a partir dos cursos de licenciatura em pedagogia, que há uma quase ausência da disciplina de didática nos cursos de pedagogia que se propõem formar professores, pois, segundo os autores, “[...] nos dados obtidos, tanto em relação ao total de disciplinas ofertadas nas matrizes curriculares como em relação à carga horária, essa disciplina representa apenas $6 \%$ do curso" (PIMENTA et al, 2017, p. 12). Apesar disso, ainda de acordo com os autores, a didática tem um papel fundamental nos cursos de pedagogia. Trazemos os dados deste estudo para os demais cursos de licenciatura, pois, como aponta Brandão (2002), acreditamos que falta nos cursos de formação de "professores pé na realidade", contextualização e enraizamento na realidade das escolas, bem como nas condições da prática profissional do professor.

Em sintonia com as contribuições de Pimenta et al (2017) e Brandão (2002), reiteramos o uso do termo "(des)lugar" da pedagogia e da didática na formação dos

${ }^{8}$ Trata-se da pesquisa desenvolvida por PIMENTA, Selma Garrido.; FUSARI, José Cerchi.; PEDROSO, Cristina Cinto Araújo.; PINTO, Umberto de Andrade, sobre "Os cursos de licenciatura em pedagogia: fragilidades na formação inicial do professor polivalente". 
professores para sublinhar a quase ausência, assim como a pouca efetividade, na maioria das vezes, da disciplina de didática na formação docente. Isso nos conclama a defender o lugar de destaque que a pedagogia e a didática devem assumir nos processos de formação docente como componente essencial, tanto em uma perspectiva teórica como prática. Entretanto, como nos chamam a atenção Araújo e Ribeiro (2016), não podemos tornar a didática prisioneira da perspectiva de prescrever teorias para guiar o processo de ensino. Ao contrário, que a didática faça emergir questionamentos, reflexões didáticas consistentes e, por consequência, que os professores busquem meios para lidar com as contradições postas à escola na contemporaneidade.

De modo semelhante, Gatti (2016, p. 04) nos chama a atenção dizendo que "[...] quando um professor é bem formado, ele detém um saber que alia conhecimento e conteúdos à didática e às condições de aprendizagem para segmentos diferenciados". Tal posição é reforçada também nos argumentos de Franco (2008) que sublinha que a pedagogia e a didática, a partir das suas responsabilidades científica e social, possibilitam a integração do educativo com o pedagógico e assim a construção de espaços de significação para as práticas docentes.

Considerando que há nas salas de aulas, muitas vezes, a ausência de um espaço pedagógico significativo e capaz de mobilizar saberes e possibilitar aos sujeitos construírem conhecimentos, convém destacarmos as necessidades formativas dos professores, em relação aos conhecimentos didático-pedagógico que, por consequência, se reverberam nos processos de ensino e de aprendizagem. Desta forma, a didática, como sinaliza Franco (2015), ajudará o professor a pensar no significado do ato de ensinar, a refletir sobre a sua prática frente à realidade, a olhar para o aluno e pensar nas suas necessidades e, por consequência, a organizar o ensino a partir desse mesmo olhar. A pedagogia, de modo correlato à didática, possibilitará ao professor atribuir intencionalidades às práticas, pôr-se em estado contínuo de reflexão, descobrindo caminhos e meios para articular teoria e prática.

Nesta perspectiva, uma formação docente fincada na pedagogia e na didática permitirá ao professor construir e reconstruir sua prática, assim como descortinar caminhos rumo a uma experiência docente de êxodo abalizada, sobretudo, na militância pedagógica, e assim o professor poderá fazer da sua própria prática pedagógica laboratório de formação. Entretanto, como bem esclarece Franco (2015, p. 605), a “[...] prática docente para se transformar em prática pedagógica, requer, pelo menos, dois 
movimentos: o da reflexão crítica de sua prática e o da consciência das intencionalidades que presidem suas práticas".

Das proposições da autora, compreendemos que não basta planejar e executar práticas, apresentar intenções pedagógicas ou tomar nota das necessidades dos alunos, se essas práticas não forem acompanhadas de uma ação efetiva de reflexão, que permita ao professor a leitura e a compreensão dos movimentos das suas práticas. Nesse passo, as práticas docentes ficam sem efeito real se elas não forem acompanhadas dos movimentos da práxis por parte de cada professor em particular, de uma tomada de consciência mais viva, dinâmica e de uma ação efetiva de análise da realidade contemporânea, assim como das necessidades dos alunos que vivem condicionados à ela. Ou seja, sem análise crítica e construtiva da realidade cotidiana e das necessidades da população discente, as práticas docentes correm o risco de se apresentarem com ideais e princípios que não dialogam com as próprias práticas.Nesse sentido, entendemos que a formação pedagógica vivenciada pelos docentes pode contribuir para que os mesmos se sintam seguros, assim como estejam cônscios das intencionalidades que presidem suas práticas. A formação docente pedagógica, deste modo, abre progressivamente as possibilidades de se melhorar a qualidade do ensino nas escolas brasileiras, pois, como sustenta Libâneo (2006, p. 867), “o que se espera de um professor é que, pelos conhecimentos que adquire e pela preparação para a atividade docente prática, vá formando um pensamento pedagógico e um modo de agir pedagógico próprio".

As contribuições de Libâneo (2006) são oportunas para reiterarmos nossa compreensão de que é por meio de uma formação vinculada à pedagogia e à didática, bem como a partir das suas reais necessidades pedagógicas que os professores poderão construir os saberes didático-pedagógicos necessários à ação docente. Assim, se concebe aqui o campo da pedagogia e da didática, mesclados vitalmente com todos os elementos que envolvem a organização pedagógica da escola, como campos constitutivos do processo de formação docente. É nessa perspectiva que Gatti (2016) adverte que as formas de participação dos professores em sala de aula, em um programa educacional, assim como a sua inserção na instituição e no sistema, são pontos vitais quando se pensa a formação dos mesmos. Daí a necessidade de se valorizar a participação dos professores na instituição, no sistema como um todo, assim como no seu processo de formação. 
Vale destacar ainda, considerando o exposto, que a formação dos professores deve ser planejada tomando como ponto de partida a própria ação docente e como ponto de chegada a construção de um "novo" fazer docente. Este processo, concordando com Araújo e Ribeiro (2016), deve possibilitar um contraponto entre a teoria e a prática, ou seja, que os professores materializem uma reflexão da prática na prática e que, por consequência, um processo educativo significativo para os alunos seja desenvolvido. Por isso, conforme argumentam ainda Araújo e Ribeiro (2016), a pedagogia e a didática devem ressurgir hoje com múltiplas feições, visando, sobretudo, oportunizar aos professores uma formação pedagógica capaz de elevar a qualidade da sua formação e, por consequência, a qualidade do ensino na educação básica.

Em uma mesma linha de raciocínio, compreendemos que uma boa base pedagógica impulsionará os professores a desenvolverem um trabalho de reflexão sobre a prática na prática, ou seja, a problematizar a própria prática pedagógica e a situá-la em um contexto teórico, com vistas a encontrar formas de transformá-la. Assim, faz-se necessário que o professor olhe para sua ação à luz da pedagogia e da didática visando combater a prática do não ver criticamente a sua própria ação pedagógica, do não ver criticamente o próprio fazer docente que o campo da pedagogia e da didática reprova com tanta veemência e que, muitas vezes, passa distante das necessidades e realidade dos discentes.

Assim, em linhas conclusivas, conforme o posicionamento que nos moveu nesta discussão, reiteramos aqui nossa compreensão que a pedagogia e a didática oferecem múltiplas escolhas teóricas e metodológicas a cada professor, por isso os mesmos podem se agarrar a elas e levá-las consigo no seu cotidiano pedagógico. Afinal de contas, a formação só faz sentido se o professor melhorar suas práticas a partir dos saberes apreendidos nessa formação. Daí a tese que a pedagogia e a da didática devem ocupar lugar de destaque na formação dos professores.

\section{Considerações Finais}

Como vimos, há uma arrazoada literatura especializada que fortalece a tese aqui apresentada sobre a necessária relação entre a pedagogia, a didática e a formação dos professores das diversas áreas do conhecimento, seja ela inicial ou contínua. As considerações realizadas até aqui nos levam a reafirmar a crença que, considerando a quase ausência e a pouca efetividade, na maioria das vezes, da pedagogia e da didática 
na formação docente, as escolas brasileiras contam com professores, muitas vezes, sem a necessária formação vinculada à pedagogia e à didática. Como vimos, muitos docentes são formandos sem compreenderem as dimensões didático-pedagógicas que perpassam o processo educativo. Tudo isso se reflete nos processos de ensino e aprendizagem dos discentes, haja vista que muitos professores passam a exercer o magistério sem os necessários conhecimentos da pedagogia e da didática. E, portanto, sem conhecerem o leque de escolhas e opções que os referidos campos colocam à disposição dos professores.

As ideias apresentadas até aqui não têm a pretensão de exaurir o debate, mas de trazer novos olhares e suscitar novas discussões que centrem o interesse investigativo por questões didático-pedagógicas ligadas à formação e às práticas docentes, assim como à qualidade e aos elementos que constituem os processos de ensino e aprendizagem. Novos debates e investigações se fazem necessárias frente ao desafio da consolidação de uma formação docente, de fato, vinculada à pedagógica e à didática que ainda continua em aberto.

Em linhas finais, registramos que a pedagogia e a didática oferecem diversos estudos teóricos e metodológicos ao professor, por isso os mesmos podem se agarrar a elas e levá-las consigo no seu cotidiano pedagógico. Afinal de contas, a formação só faz sentido se o professor melhorar suas práticas a partir dos saberes apreendidos nessa formação. Enfim, reafirmamos nossa crença que a formação docente, a pedagogia e a didática são campos indivisíveis, haja vista que não podem se separar ou até mesmo se contrapor, pois a pedagogia e a didática apresentam fundamentos teóricos $\mathrm{e}$ metodológicos capazes de contribuir para a transformação da escola em um contexto de novas vivências e fértil para a construção coletiva de conhecimentos e saberes.

\section{Referências}

ARAÚJO, Osmar Hélio Alves.; RIBEIRO, Luís Távora Furtado. A didática e a pedagogia como suporte teórico para uma coordenação pedagógica qualificada. Revista on line de Política e Gestão Educacional, Araraquara, v.20, n.2, p. 501-513, 2016. Disponível em: <http://dx.doi.org/10.22633/rpge.v20.n3.9533>. ISSN: 1519-9029. Acesso em: 29 abr. 2017.

CANDAU, Vera Maria. A didática e a formação de educadores: Da exaltação à negação: a busca da relevância. In: CANDAU, Vera Maria (Org.). A didática em questão. 28. Ed. Petrópolis, RJ: Vozes, 2008. 
FRANCO, Maria Amélia do Rosário Santoro. Pedagogia como ciência da educação. 2 ed. São Paulo: Papirus, 2008.

FRANCO, Maria Amélia do Rosário Santoro.; LIBÂNEO, José Carlos.; PIMENTA, Selma Garrido. As dimensões constitutivas da Pedagogia como campo de conhecimento. Revista Educação em foco, Belo Horizonte, ano 14, n. 17, p. 55-78, jul. 2011 .

FRANCO, Maria Amélia do Rosário Santoro.; GILBERTO, Irene Jeanete Lemos. A prática docente e a construção dos saberes pedagógicos. Revista Teias v. 12 - n. 25 • 212-224 • maio/ago. 2011 - Ética, Saberes \& Escola. Disponível em: $<$ http://www.periodicos.proped.pro.br/index.php/revistateias/article/view/705>. Acesso em: 02 maio 2016.

FRANCO, Maria Amélia Santoro; PIMENTA, Selma Garrido (Orgs). Didática: embates contemporâneos. São Paulo: Edições Loyola, 2012. Apresentação.

FRANCO, Maria Amélia do Rosário Santoro. Práticas pedagógicas de ensinar-aprender: por entre resistências e resignações. Educ. Pesqui., São Paulo, v. 41, n. 3, p. 601-614, jul./set. 2015. Disponível em: <http://www.scielo.br/pdf/ep/v41n3/1517-9702-ep-41-30601.pdf>. Acesso em: 03 maio de 2016.

GATTI, Bernadete A. Formação de professores: condições e problemas atuais. Revista Internacional de Formação de Professores (RIFP), Itapetininga, v. 1, n.2, p. 161-171, 2016. Disponível em: <http://itp.ifsp.edu.br/ojs/index.php/RIFP/article/view/347>. Acesso em: 24 abr. 2017.

LIBÂNEO, José Carlos. Produção de saberes na escola: suspeitas e apostas. In: CANDAU, Vera Maria (org.) Didática, currículo e saberes escolares. 2. ed. Rio de Janeiro: DP\&A, 2002.

LIBÂNEO, José Carlos. DIRETRIZES CURRICULARES DA PEDAGOGIA: imprecisões teóricas e concepção estreita da formação profissional de educadores. Educ. Soc., Campinas, vol. 27, n. 96 - Especial, p. 843-876, out. 2006. Disponível em: $<$ http://www.cedes.unicamp.br>. Acesso em:21 dez. 2015.

MASCARENHAS, Aline Daiane Nunes.; FRANCO, Maria Amélia Santoro. DE PEDAGOGOS A PROFESSORES: balanço de uma década das diretrizes curriculares dos cursos de pedagogia no Brasil. Revista Internacional de Formação de Professores (RIFP), Itapetininga, v. 2, n.1, p. 41-55, 2017. Disponível em:〈http://www.scielo.br/pdf/ep/v41n3/1517-9702-ep-41-3-0601.pdf >. Acesso em: 28 abr. 2017.

PIMENTA, Selma Garrido; ANASTASIOU, Léa das Graças Camargos. Docência no ensino superior. São Paulo: Cortez, 2002.

PIMENTA, Selma Garrido. Formação de professores - saberes da docência e identidade do professor. In: PIMENTA, S. G. (Org.). Saberes pedagógicos e atividade docente. São Paulo: Cortez, 1999. 
PIMENTA, Selma Garrido. Epistemologia da prática ressignificando a Didática. FRANCO, Maria Amélia Santoro; PIMENTA, Selma Garrido (Orgs). Didática: embates contemporâneos. São Paulo: Edições Loyola, 2012.

PIMENTA, Selma Garrido.; FUSARI, José Cerchi.; PEDROSO, Cristina Cinto Araújo.; PINTO, Umberto de Andrade. Os cursos de licenciatura em pedagogia: fragilidades na formação inicial do professor polivalente. Educ. Pesqui., São Paulo, v. 43, n. 1, p.1530, jan./mar. 2017. Disponível em: < http://dx.doi.org/10.1590/S15179702201701152815>. Acesso em: 29 abr. 2017.

BRANDÂO, Zaia. Abordagens alternativas para o ensino da didática. In: Vera Maria (Org.). A didática em questão. 28. Ed. Petrópolis, RJ: Vozes, 2002.

\section{Como referenciar este artigo}

ARAÚJO, Osmar Hélio Alves.; RODRIGUES, Janine Marta Coelho.; ARAGÃO, Wilson Honorato. O (des)lugar da pedagogia e da didática na formação dos professores. Revista on line de Política e Gestão Educacional, Araraquara, v.21, n.01, p. 215-226, 2017. Disponível em: <http://dx.doi.org/10.22633/rpge.v21.n.1.2017.9534>. ISSN: 1519-9029.

Submetido em: 30/11/2016

Aprovado em: 30/03/2017 